\title{
Teacher Interaction in Technology-Supported Learning Environment (TSLE): A Social Constructivist Perspective
}

\author{
Lalitha Devi B. ${ }^{1} \&$ Madhumathi P. ${ }^{2}$
}

\author{
${ }^{1,2} \mathrm{H} \&$ SS Department, NIT Warangal, India \\ Correspondence: Lalitha Devi B., NIT Warangal, India. \\ Email: lalithadevi.bommanaboina@gmail.com
}

DOI: $10.53103 /$ cjess.v1i1.1

\begin{abstract}
In the $21^{\text {st }}$ century, the processes of learning is redefined and modified with the advancement in educational technology. The limitations of physical environment are substituted by online environment by providing opportunities to interact and discuss more widely and constructively. Discussion of content, and application of content is gaining importance along with knowing the content. In present scenario one can access courses available online and participate in discussions which may result in knowledge accumulation, building professional relationships and exposure to one's own field. Research shows significance of online interactions in teacher education and how it is closely viewed from the lenses of Social Constructivist Theory. But limited research is conducted to know how online platforms and other factors affect interactions of student teachers and in-service teachers. The present research conducts a review analysis to know about the online platform and other factors which impact interactions of both student teachers and in-service teachers in technology-supported learning environment. Through observations it is concluded that knowledge sharing coupled with knowledge construction in groups/collaborative platforms need to be encouraged keeping in view the factors which influence such process. Social interactions are essential for professional growth but while including them in educational courses the attitudes, motivational levels of course participants should be taken into consideration. This will help adding value to the process.
\end{abstract}

Keywords: Teacher Education, Social Constructivism, Technology-supported Learning Environment (TSLE), Interaction, Pre-service Teacher/Student Teacher, In-service Teacher

\section{Introduction}

Teacher Education falls into two categories: Pre-service and In-service. Teacher being a student has to co-construct knowledge along with the other teachers and teacher educator/trainer. As dynamic learning environments are coming into picture, the field of Teacher Education needs continuous experimentation on the nature of group interactions 
and their impact on teacher development. A student-teacher being exposed to traditional modes of interaction that is face to face interaction finds it challenging to interact or participate in discussions in technology-supported learning environment. Opinion-sharing, interaction and communication fall under socio-emotional literacy (Eshet, 2004). Constructing knowledge is an active process which is an outcome of personal experiences and professional experiences. With the advent of modern technology, there is a lot of scope to express, share and learn through formal and informal channels. Constructivism in a nutshell is a process which involves awareness of the changes in the concerned field, dynamism, and reflection on various aspects of one's profession. Moreover, constructivism adds validity to the process of learning. Thus, if this process is done in groups, it turns to be a social constructivism (Kalina \& Powell, 2009). This way, learning is constructed on a collective basis and reconstructed on an individual basis. Social Constructivism was explained by (Beck \& Kosnik, 2006) as a process which should be built on the principles of integration, inquiry and community. The authors define social constructivism as "a passionate approach, involving the whole person: thought, emotion, and action" (p. 8). Applefield et al. (2000) opine that learners in a social setting will build meanings together. It is the process which helps to deconstruct or construct. Discussions with practicing teachers will help in shaping the beliefs of pre-service teachers who come with no or little knowledge to teacher training courses (Richardson, 1996).

After reviewing articles on themes such as social constructivism, ICT platforms and Teacher Education separately and together sorted out many factors which impact teacher interaction. The learning environments include many features. The present study considers tools and platforms of TSLE through which the interactions happen: ICT platforms (Moodle, MOOCs, and virtual classrooms), and traditional technology (mobiles) $\&$ traditional technology platforms (blogs, twitter, Facebook, whatsApp).

Social networking sites and learning through mobile are relevant to any point of time in future and can be explored in different ways for teaching and learning processes. All types of interaction are possible on technology-supported learning environment. It provides an opportunity to get a revised, reframed and improvised version of an idea, concept, theory or an activity (Nicaise \& Barnes, 1996). This kind of practice is important among teachers. While designing a training programme for teachers or for designing a course for learners, utmost importance should be given to encourage learning through discussions or interactions. The new knowledge can be constructed from available or current-theoretical knowledge (content, pedagogy, technology), and practical knowledge (content, pedagogy, technology).

The research question addressed in this paper is:

What are the various factors grounded in the social constructivist theory that affect teacher interactions? 


\section{Curriculum Frameworks and TSLE}

TPCK (Mishra \& Koehler, 2006), which stands for Technological Pedagogical Content Knowledge is a framework, which integrates content (what to teach), and pedagogy (how to teach) with technology. The authors opine that applying technology to teaching is important than studying about technology. Willermark (2017) reports that the research is more on measurement of TPACK knowledge and that should witness a shift towards measurement of TPACK competence.

A framework named CIDA (Michos \& Hernández-Leo, 2020) is put forward with an aim to inform teachers about the impact of technology which they use or an activity they take up on online platform for a particular teaching purpose on their teaching and learners' learning. These frameworks take into consideration the study of teachers' participation on collaborative online platforms, and their online activities. With the help of this framework teachers can reflect on the data generated and stored. This will help teachers and teacher educators in studying technology supported learning environments. There is a comprehensive framework namely ICAP (Interactive, Constructive, Active, Passive) (Chi \& Wylie, 2014) which talks of various activities that are aimed at the improvement in students' thinking processes.

Community of Inquiry Framework (Garrison et al., 1999) is significant in terms of its inclusion of three essential aspects - teaching presence, cognitive presence and social presence to be considered while planning interactions. All these curriculum frameworks are designed to see the connection technology and teacher education. Teacher educators need to tailor those frameworks as per needs of learners.

\section{Teacher Interaction in Technology-Supported Learning Environment}

Teacher Education courses can happen in different ways such as face-to-face, online and blended. Predominantly it is an online module which is included in face-to-face training programmes. Other terms which are widely used are synchronous and asynchronous learning. As $21^{\text {st }}$ century learning is synonymous with digital learning it is imperative that teacher education courses give due importance to online learning of teachers along with online teaching by teachers. Teachers' learning online is a dynamic process and multidimensional. Mostly emphasis is laid on what is learned rather than how it is learned. To put it simply both product and process of learning should receive equal attention. Teachers can only implement what they practice. Basically learning involves knowing, discussing and practicing (England, 2012). A good combination of these three can have short term as well as long term benefits and changes. When it comes to discussion/interaction part of teacher training courses or programmes, it can be a source of 
data about what teachers think about a particular aspect or what are teacher's beliefs and attitudes. Coming to the other aspect, interactions and discussions will help teachers to communicate their thoughts, experiences, opinions and build a sense of community.

Teacher Education in TSLE can happen through courses, workshops, programmes, webinars and modules. Social media and ICT platforms are part of these initiatives. MOOCs are widely recognized as open courses are available to teachers of any level of experience. Technology-supported learning environments provide a scope for trainers, teachers and learners to stay connected. Indeed the training programmes should realize the importance of these in-field connections. In teacher education courses that are based on a traditional learning environment, there is a scope for connectivity of any two parties student teacher and teacher educator or learner and teacher or teacher trainer and student teacher. Moreover, in technology supported learning environment there is a good chance to create a platform to bring together any number of parties involved in the process of education. The best examples are MOOC, online workshops and virtual classrooms. In addition, there should be specific objectives for which such platforms are created, so that they can be used effectively for forum discussions.

Student teachers feel it as a challenge or an opportunity in using a particular social media platform for academic and professional purposes. So, teacher educators should raise the needed awareness (Carpenter et al., 2016). It is believed that student teachers learn more from their exposure of how technology is used by the skilled teachers (Nelson \& Hawk, 2020). Until, Teacher Educators feel that student teachers become confident enough in expressing their views, they should be given proper support or scaffolding (Adams, 2006). Järvelä \& Häkkinen (2002) analyzed the interaction of pre-service teachers on a web-based conferencing platform and found that discussions among participants were of different levels ranging from low to high. It is quite important for teacher trainers/educators to check the quality of interactions for the quality learning of pre-service and in-service teachers. Biberman-Shalev (2018) found in their research that pre-service teachers who were made part of communal blogging viewed the practice as an important aspect of building support and helping each other in learning.

\section{Factors That Impact Teacher Interaction}

Schweizer et al. (2002) relate quality of online course to initiatives taken by course instructors in providing supportive and meaningful environment to pre-service teachers to participate in discussions. The comfortable levels in using technological tools and the reasons behind choice of online teacher education course act as an important factor to plan for inclusion of online discussions as part of teacher education courses. Baltaci-Goktalay \& Ozdilek (2010) conducted a survey with 120 pre-service teachers in Turkey and found that pre-service teachers are inclined towards using web 2.0 technologies as part of their 
learning. Banegas \& Manzur Busleimán (2014) state that in a country like Patagonia, teacher education course is available only in online mode, there is less priority for collaborative learning. Rather course completion remains the priority. A similar study (Ebrahimi et al., 2017) conducted with 32 Iranian pre-service teachers has revealed the fact that students perceived online discussion forum for discussion of content and topics rather than building of social connections with peers.

Hew \& Cheung (2013) mention that audio-based discussions and text-based discussions will be realized differently based on the comfortable levels of participants towards the medium. Teacher Educators can encourage video-based discussions and make a provision for different learning styles of student teachers (Kalelioglu \& Tekmen, 2012). It is important for teacher educators to study the motivational levels of pre-service teachers and in-service teachers regarding their participation in online discussions which help in understanding the efficient use of online discussion forums (Assaf, 2005). Sivan (1986) opines that the motivational levels of an individual are decided by factors such as culture, interpersonal relationships and individual psychological aspects under social constructivist theory. Mumford \& Dikilitaş (2020) stress the challenges present in constructing social environment in online interaction and further state that pre-service teachers need training regarding online interaction. One of the challenges faced by course instructors of MOOC courses is to get student participation on online forums (Hew \& Cheung, 2014) which indirectly indicates the fact that the number of participants impacts the online discussions. Whereas this is not a challenge in formal online courses designed in which limited number of participants take part, discussions can be planned or supported with a flexible, comprehensive, and innovative plan. Especially active interaction can happen only when there is sharing of opinions or responding to others' messages or asking questions (Guilleumas et al., 2020). It is necessary for Teacher Educators and trainers to study the participation behavior of teachers on online platforms and their progress in terms of realizing and fulfilling the objectives of online discussions ( Bryant \& Bates, 2015).

Techniques which promote creative thinking such as picture-based discussion can induce participants in discussion and encourage collaboration in technology-based learning environments (Caldwell et al., 2020). Zhang \& Liu (2019) suggest that teacher's engagement in online learning communities can be improved by giving special attention to the selection of tasks which suits the needs of teachers and also improves the self-efficacy levels of teachers. Baker-Doyle \& Yoon (2020) highlight the importance of building trust among teachers before laying emphasis on their self-efficacy levels.

Atapattu et al.(2019) report, on the basis of analysis of MOOC posts contributed by 1045 teacher participants as part of professional development course and found that teachers' may interact more if they are encouraged to share their personal classroom experiences and views. In their study Deng \& Yuen (2013) found that acquaintance among learners will impact their interactions, which should be given due importance in training 
programmes. The varied experiences of participants including teacher educators can be rightly blended to achieve meaningful interactions (McGraw et al. 2007). Maor (2003) opines that only teachers can create favorable atmosphere but it is the students who should show interest in collaborative learning. Woo \& Reeves (2007) elaborate the definition of interaction in online-learning environment by looking it from a social-constructivist approach. The researchers opine that authentic activities should be given to encourage meaningful interaction on online learning environments. Knowledge construction based on previous experiences is a continuous process. Formal interaction among teachers, informal interaction related to content, pedagogy or technology among teachers can be encouraged. But all the interaction which is intended may not lead to knowledge sharing or for professional development. van Bommel et al., (2020) conducted an analysis of conversations across six facebook groups, they came to know that $88 \%$ of the conversations centred on sharing of information, whereas only longer conversations (11\%) resulted in new knowledge construction. This clearly shows the importance of setting realistic objectives for the training courses.

Fisher \& Kim (2013) studied the impact of blogging on professional learning of pre-service language teachers of US and UK with two different approaches. The researchers found that there is exchange of ideas in both situations but the focus varied from reflective approach to the approach of co-constructing knowledge. Their study informs that the purpose for which an online platform is used varies and has different implications in different settings or situations.

The researchers Bett \& Makewa (2020) noted that in a developing country like Kenya where there are identified challenges related to teacher's CPD, Facebook can be effectively used for the professional development of teachers through discussions. Saini \& Abraham (2019) found in their interventional study conducted with 68 first year pre-service teachers studying in a state university in India that, Facebook can be used to encourage student teacher's professional engagement through interactions. Deng \& Tavares (2013) observed 14 pre-service teachers' interaction and discussion on two different platforms that is Moodle and Facebook. They found that teachers felt free to interact more on Facebook than on Moodle. The authors suggest that discussion forums with personal element/appeal should be part of training courses. They opined that it will further teachers' participation and interaction. Cakir (2013) enunciates blogging which demands no technical competence can be used as an extension to classroom discussions. The researcher found that motivational levels of 88 selected participants, their attitude towards use of blogs and reasons behind use of blogs show much impact on their usage of the platform. Ajayi (2009) conducted a study on the use of ADB (asynchronous discussion board) for professional learning with 33 pre-service teachers. The research highlights the feature of flexibility of ADBs for interaction in groups. 
Greenhalgh et al. (2020) talk about the use of twitter as a platform for 2015-16 by Michigan teachers as participants with hashtag \# michED. They suggest that Teacher Educators should be aware of the various facets of using a platform like Twitter for interaction. Krutka et al. (2014) found through their research that interactions on Edmodo platform helped pre-service teachers to take better decisions about profession and to come out of insecure feelings about their profession. Though some pre-service teachers desired support from instructor over peer support. Even gender can be one of the factors which can decide active participation (Çuhadar, 2012; Im \& Lee, 2003).

\section{Discussion and Conclusion}

Based on the interventions related to the concept of interaction and discussions in technology-based environments (traditional \& modern), the following issues can be considered:

Not all interaction leads to knowledge building, so the objectives should be specific while designing interactive tasks.

There is still relevance for tools like blogs, Facebook to encourage interactions in a formal setup.

Not every platform can be made use of to encourage constructive dialogue.

Teacher Educators/trainers can use a blend of traditional and modern learning environments for social interaction among student teachers.

Personal element is important to encourage interactions among learners.

Countries with less scope for professional development can make use of social media for professional growth of teachers.

Attitude and motivation of participants need to be considered carefully

Instructor need to build support and trust

Self-efficacy levels of participants can play a part in the way they participate in discussion on new online platforms

Way of posing questions should be innovative and engaging participants.

Student teachers should be given enough exposure to technological platforms

Teacher educators should carefully consider the quality of discussions

Student teachers and teachers prefer sharing experiences, which is an important aspect of social interaction.

Key issues related to classroom teaching or local contexts to which prospective teachers will be exposed or beginner teachers are exposed to can be considered for discussions. The discussions can also centre round technology and blended environments in which they teach.

The review is narrowed down to the online platform used for interaction in teacher education to promote constructivist thinking. Whether it is any learning environment there 
should be quality teaching and quality learning. Indeed teachers can be motivated to critically reflect on different learning environments without which the training remains incomplete. Collaborative interaction plays a positive role in professional development of teachers (Vinagre, 2017; Greene, 2007). Both students and teachers play a significant role on improving the quality of online discussions (Nandi et al. 2012). Analysis of the discussions related to nature of participation is needed, so that all participants will be equally motivated to engage in discussion (Raković et al., 2020). The learning environment should be adapted as per the learning theory which it highlights (Guney \& Al, 2012). It is high time to draw connections between principles of constructivism, Learning Environment and teacher training and to see how such connections thrive in separate learning environments or blended learning environments (Kirkley \& Kirkley, 2005).

Need for documentation is very important in the field of education for further analysis along with follow-up support, feedback delivery and monitoring. Data collection and analysis is also a great facility that can be explored and experimented on through technology-supported learning environments (Nie, 2020). This process can be better done in a technology-supported learning environment than in traditional learning environment. The data gathered can be used for the purpose of critical reflection.

Human mind is unique and in education field this fact is least considered and there is always an effort to define the learning processes in a concrete manner. Thus, technology induced learning came into picture though its achievements in the field of education are incomplete. Much emphasis has to be drawn towards making teaching and learning processes meaningful and impactful which takes our vision beyond technology or beyond a particular theory. Both knowledge and practice should be incorporated into training programmes.

\section{Further Study}

The following aspects can be considered for further study:

1. It is need of the hour to study what conditions/needs/objectives will foster interaction among pre-service teachers and in-service teachers (primary \& secondary levels) in formal teacher education courses.

2. Linking up constructivism to learning environment and pedagogy or vice versa can be done for specific objectives which can be useful for certain contexts and can successfully work for some level of learners or works successfully with certain learning environments or with certain pedagogical activities.

Further research can work on the limitations of application of constructivism as learning theory in learning environments in the field of education with an objective where actually constructivism can be effectively implemented for effective teaching and learning processes. 


\section{References}

Adams, P. (2006). Exploring social constructivism: theories and practicalities. Education 3-13, 34(3), 243-257. https://doi.org/10.1080/03004270600898893

Ajayi, L. (2009). An exploration of pre-service teachers' perceptions of learning to teach while using asynchronous discussion board. Journal of Educational Technology \& Society, 12(2), 86-100.

Applefield, J. M., Huber, R., \& Moallem, M. (2000). Constructivism in Theory and Practice: Toward a Better Understanding. The High School Journal, 84(2), 3553. http://www.jstor.org/stable/40364404

Assaf, L. C. (2005). Staying connected: Student teachers' perceptions of computermediated discussions. The Teacher Educator, 40(4), 221-237. https://doi.org/10.1080/08878730509555363

Atapattu, T., Thilakaratne, M., Vivian, R., \& Falkner, K. (2019). Detecting cognitive engagement using word embeddings within an online teacher professional development community. Computers \& Education, 140, 103594. https://doi.org/https://doi.org/10.1016/j.compedu.2019.05.020

Baker-Doyle, K. J., \& Yoon, S. A. (2020). The social side of teacher education: Implications of social network research for the design of professional development. International Journal of Educational Research, 101, 101563. https://doi.org/https://doi.org/10.1016/j.ijer.2020.101563

Banegas, D. L., \& Manzur Busleimán, G. I. (2014). Motivating factors in online language teacher education in southern Argentina. Computers \& Education, 76, 131-142. https://doi.org/https://doi.org/10.1016/j.compedu.2014.03.014

Beck, C., \& Kosnik, C. (2006). Innovations in teacher education: A social constructivist approach. Suny Press.

Bett, H., \& Makewa, L. (2020). Can Facebook groups enhance continuing professional development of teachers? Lessons from Kenya. Asia-Pacific Journal of Teacher Education, 48(2), 132-146. https://doi.org/10.1080/1359866X.2018.1542662

Biberman-Shalev, L. (2018). Personal blogs or communal blogs? Pre-service teachers' perceptions regarding the contribution of these two platforms to their professional development. Teaching and Teacher Education, 69, 253-262. https://doi.org/https://doi.org/10.1016/j.tate.2017.10.006

Bryant, J., \& Bates, A. J. (2015). Creating a constructivist online instructional environment. TechTrends, 59(2), 17-22. https://doi.org/10.1007/s11528-0150834-1

Cakir, H. (2013). Use of blogs in pre-service teacher education to improve student engagement. Computers \& Education, 68, 244-252. https://doi.org/https://doi.org/10.1016/j.compedu.2013.05.013

Caldwell, H., Whewell, E., \& Heaton, R. (2020). The impact of visual posts on creative thinking and knowledge building in an online community of educators. Thinking 
Skills and Creativity, 36, 100647.

https://doi.org/https://doi.org/10.1016/j.tsc.2020.100647

Carpenter, J. P., Tur, G., \& Marín, V. I. (2016). What do U.S. and Spanish pre-service teachers think about educational and professional use of Twitter? A comparative study. Teaching and Teacher Education, 60, 131-143. https://doi.org/https://doi.org/10.1016/j.tate.2016.08.011

Chi, M. T. H., \& Wylie, R. (2014). The ICAP framework: Linking cognitive engagement to active learning outcomes. Educational Psychologist, 49(4), 219-243. https://doi.org/10.1080/00461520.2014.965823

Deng, L., \& Tavares, N. J. (2013). From Moodle to Facebook: Exploring students' motivation and experiences in online communities. Computers \& Education, 68, 167-176. https://doi.org/https://doi.org/10.1016/j.compedu.2013.04.028

Deng, L., \& Yuen, A. H. K. (2013). Blogs in pre-service teacher education: Exploring the participation issue. Technology, Pedagogy and Education, 22(3), 339-356. https://doi.org/10.1080/1475939X.2013.802990

Ebrahimi, A., Faghih, E., \& Dabir-Moghaddam, M. (2017). Student perceptions of effective discussion in online forums: A case study of pre-service teachers. Innovations in Education and Teaching International, 54(5), 467-475. https://doi.org/10.1080/14703297.2016.1143858

England, L. (2012). Online Language Teacher Education: TESOL Perspectives. Routledge. https://books.google.co.in/books?id=lstq3_RU7t4C

Eshet, Y. (2004). Digital literacy: A conceptual framework for survival skills in the digital era. Journal of Educational Multimedia and Hypermedia, 13(1), 93-106.

Fisher, L., \& Kim, D. (2013). Two approaches to the use of blogs in pre-service foreign language teachers' professional development: A comparative study in the context of two universities in the UK and the US. The Language Learning Journal, 41(2), 142-160. https://doi.org/10.1080/09571736.2013.790130

Garrison, D. R., Anderson, T., \& Archer, W. (1999). Critical Inquiry in a Text-Based Environment: Computer Conferencing in Higher Education. The Internet and Higher Education, 2(2), 87-105. https://doi.org/https://doi.org/10.1016/S10967516(00)00016-6

Greene, H. C. (2007). The role of socially constructed shared knowledge in learning to teach: collaboration and reflection in a computer-mediated environment. The Teacher Educator, 43(1), 1-28. https://doi.org/10.1080/08878730701728747

Greenhalgh, S. P., Rosenberg, J. M., Staudt Willet, K. B., Koehler, M. J., \& Akcaoglu, M. (2020). Identifying multiple learning spaces within a single teacher-focused Twitter hashtag. Computers \& Education, 148, 103809. https://doi.org/https://doi.org/10.1016/j.compedu.2020.103809

Guilleumas, R., Sánchez-Gómez, M. C., Mena, J., \& Pinto-Llorente, A. (2020). Students' Perception of Distributed Teaching Presence in Discussion Forums. A Case Study (pp. 249-270). https://doi.org/10.1007/978-3-030-45781-5_12

Guney, A., \& Al, S. (2012). Effective learning environments in relation to different learning theories. Procedia - Social and Behavioral Sciences, 46, 2334-2338. https://doi.org/https://doi.org/10.1016/j.sbspro.2012.05.480 
Hew, K. F., \& Cheung, W. S. (2013). Audio-based versus text-based asynchronous online discussion: two case studies. Instructional Science, 41(2), 365-380. https://doi.org/10.1007/s11251-012-9232-7

Hew, K. F., \& Cheung, W. S. (2014). Students' and instructors' use of massive open online courses (MOOCs): Motivations and challenges. Educational Research Review, 12, 45-58. https://doi.org/https://doi.org/10.1016/j.edurev.2014.05.001

Im, Y., \& Lee, O. (2003). Pedagogical implications of online discussion for preservice teacher training. Journal of Research on Technology in Education, 36(2), 155170. https://doi.org/10.1080/15391523.2003.10782410

Järvelä, S., \& Häkkinen, P. (2002). Web-based cases in teaching and learning - the quality of discussions and a stage of perspective taking in asynchronous communication. Interactive Learning Environments, 10(1), 1-22. https://doi.org/10.1076/ilee.10.1.1.3613

Kalelioglu, F., \& Tekmen, B. (2012). Perceptions of the pre-service teachers about video based classroom discussions. Procedia - Social and Behavioral Sciences, 46, 2015-2019. https://doi.org/https://doi.org/10.1016/j.sbspro.2012.05.420

Kalina, C., \& Powell, K. C. (2009). Cognitive and social constructivism: Developing tools for an effective classroom. Education, 130(2), 241-250.

Kirkley, S. E., \& Kirkley, J. R. (2005). Creating next generation blended learning environments using mixed reality, Video Games and Simulations. TechTrends, 49(3), 42-53. https://doi.org/10.1007/BF02763646

Krutka, D. G., Bergman, D. J., Flores, R., Mason, K., \& Jack, A. R. (2014). Microblogging about teaching: Nurturing participatory cultures through collaborative online reflection with pre-service teachers. Teaching and Teacher Education, 40, 83-93. https://doi.org/https://doi.org/10.1016/j.tate.2014.02.002

Maor, D. (2003). Teacher's and students' perspectives on on-line learning in a social constructivist learning environment. Technology, Pedagogy and Education, 12(2), 201-218. https://doi.org/10.1080/14759390300200154

McGraw, R., Lynch, K., Koc, Y., Budak, A., \& Brown, C. A. (2007). The multimedia case as a tool for professional development: an analysis of online and face-toface interaction among mathematics pre-service teachers, in-service teachers, mathematicians, and mathematics teacher educators. Journal of Mathematics Teacher Education, 10(2), 95-121. https://doi.org/10.1007/s10857-007-9030-3

Michos, K., \& Hernández-Leo, D. (2020). CIDA: A collective inquiry framework to study and support teachers as designers in technological environments. Computers \& Education, 143, 103679. https://doi.org/https://doi.org/10.1016/j.compedu.2019.103679

Mishra, P., \& Koehler, M. J. (2006). Technological pedagogical content knowledge: A framework for teacher knowledge. Teachers College Record, 108(6), 1017-1054.

Mumford, S., \& Dikilitaş, K. (2020). Pre-service language teachers reflection development through online interaction in a hybrid learning course. Computers \& Education, 144, 103706.

https://doi.org/https://doi.org/10.1016/j.compedu.2019.103706 
Nandi, D., Hamilton, M., \& Harland, J. (2012). Evaluating the quality of interaction in asynchronous discussion forums in fully online courses. Distance Education, 33(1), 5-30. https://doi.org/10.1080/01587919.2012.667957

Nelson, M. J., \& Hawk, N. A. (2020). The impact of field experiences on prospective preservice teachers' technology integration beliefs and intentions. Teaching and Teacher Education, 89, 103006. https://doi.org/https://doi.org/10.1016/j.tate.2019.103006

Nicaise, M., \& Barnes, D. (1996). The Union of Technology, Constructivism, and Teacher Education. Journal of Teacher Education, 47(3), 205-212. https://doi.org/10.1177/0022487196047003007

Nie, Y. (2020). On-line classroom visual tracking and quality evaluation by an advanced feature mining technique. Signal Processing: Image Communication, 84, 115817. https://doi.org/https://doi.org/10.1016/j.image.2020.115817

Raković, M., Marzouk, Z., Liaqat, A., Winne, P. H., \& Nesbit, J. C. (2020). Fine grained analysis of students' online discussion posts. Computers \& Education, 157, 103982. https://doi.org/https://doi.org/10.1016/j.compedu.2020.103982

Richardson, V. (1996). From behaviorism to constructivism in teacher education. Teacher Education and Special Education, 19(3), 263-271. https://doi.org/10.1177/088840649601900324

Saini, C., \& Abraham, J. (2019). Implementing Facebook-based instructional approach in pre-service teacher education: An empirical investigation. Computers \& Education, 128, 243-255. https://doi.org/https://doi.org/10.1016/j.compedu.2018.09.025

Schweizer, H., Whipp, J., \& Hayslett, C. (2002). Quality Control in Online Courses. Computers in the Schools, 19(3-4), 143-158. https://doi.org/10.1300/J025v19v03_12

Sivan, E. (1986). Motivation in Social Constructivist Theory. Educational Psychologist, 21(3), 209-233. https://doi.org/10.1207/s15326985ep2103_4

Theelen, H., van den Beemt, A., \& Brok, P. den. (2020). Developing preservice teachers' interpersonal knowledge with 360-degree videos in teacher education. Teaching and Teacher Education, 89, 102992. https://doi.org/https://doi.org/10.1016/j.tate.2019.102992

van Bommel, J., Randahl, A.C., Liljekvist, Y., \& Ruthven, K. (2020). Tracing teachers' transformation of knowledge in social media. Teaching and Teacher Education, 87, 102958. https://doi.org/https://doi.org/10.1016/j.tate.2019.102958

Willermark, S. (2017). Technological pedagogical and content knowledge: A review of empirical studies published From 2011 to 2016. Journal of Educational Computing Research, 56(3), 315-343. https://doi.org/10.1177/0735633117713114

Woo, Y., \& Reeves, T. C. (2007). Meaningful interaction in web-based learning: A social constructivist interpretation. The Internet and Higher Education, 10(1), 15-25. https://doi.org/https://doi.org/10.1016/j.iheduc.2006.10.005

Zhang, S., \& Liu, Q. (2019). Investigating the relationships among teachers' motivational beliefs, motivational regulation, and their learning engagement in online 
professional learning communities. Computers \& Education, 134, 145-155.

https://doi.org/https://doi.org/10.1016/j.compedu.2019.02.013 